Research Article

\title{
Two-Port CPW-Fed Dual-Band MIMO Antenna for IEEE 802.11 a/b/g Applications
}

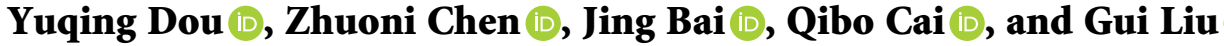 \\ College of Electrical and Electronics Engineering, Wenzhou University, Wenzhou 325035, China \\ Correspondence should be addressed to Gui Liu; iitgliu2@gmail.com
}

Received 19 January 2021; Revised 8 May 2021; Accepted 29 May 2021; Published 10 June 2021

Academic Editor: Muhammad Zubair

Copyright (C) 2021 Yuqing Dou et al. This is an open access article distributed under the Creative Commons Attribution License, which permits unrestricted use, distribution, and reproduction in any medium, provided the original work is properly cited.

A coplanar waveguide- (CPW-) fed dual-band multiple-input multiple-output (MIMO) antenna for 2.45/5.5 GHz wireless local area network (WLAN) applications is presented in this paper. The presented MIMO antenna consists of two identical trapezoidal radiating elements which are perpendicular to each other. The size of the entire MIMO antenna is $50 \times 50 \times 1.59 \mathrm{~mm}^{3}$, which is printed on a FR4 substrate. The measured impedance bandwidth of the proposed antenna is $2.25-3.15 \mathrm{GHz}$ and $4.89-5.95 \mathrm{GHz}$, which can cover IEEE $802.11 \mathrm{a} / \mathrm{b} / \mathrm{g}$ frequency bands. A rectangular microstrip stub is introduced to achieve a good isolation which is less than $-15 \mathrm{~dB}$ in both operation frequency bands. The measured peak gain is $5.59 \mathrm{dBi}$ at $2.45 \mathrm{GHz}$ and $5.63 \mathrm{dBi}$ at $5.5 \mathrm{GHz}$. The measured antenna efficiency is $77.8 \%$ and $80.4 \%$ in the lower and higher frequency bands, respectively. The ECC values at the lower and higher frequencies are lower than 0.003 and 0.01 , respectively.

\section{Introduction}

The development of modern wireless communication systems requires high-speed and high-reliability data transmission. Due to the limitation of spectrum resources, there are higher requirements for wireless communication technology. Since there are several wireless communication systems in a mobile terminal, designing and placing many internal antennas in a limited space remains a big challenge. Dual-band antenna is one of the solutions of reducing the antenna numbers in a terminal. Many dual-band mobile terminal antenna structures have been reported, including hook-shaped strip structure [1], an open-loop ring resonator feeding element and a T-shaped radiating element [2], and substrate-integrated suspended line structure [3].

Multiple-input multiple-output antennas have been widely studied in recent years, which can increase the channel capacity and data transmission rate [4-14]. Due to the use of multi-port structures, placing many antenna elements close to each other would increase the mutual coupling between the elements and affect the performance of the MIMO antenna. A decoupling structure is needed to enhance the isolation between radiator elements of MIMO antenna. In recent years, many decoupling techniques have been proposed, including defected ground structure $[4,5]$, electromagnetic bandgap structure $[6,7]$, open-slot [8], $\pi$-shaped decoupling structure [9], and neutral line [10]. In [11], the stub-loaded meander-line antenna is loaded with split-ring resonators (SRRs) arranged in the form of a ring to enhance isolation by $17 \mathrm{~dB}$ at $2.4 \mathrm{GHz}$. In [12], by sharing one common grounding branch for the two adjacent antenna elements, a compact self-decoupled antenna pair can be obtained.

There are many technologies to implement dual-band MIMO antennas. For example, a microstrip line feed antenna with two quarter-wavelength slots is used as an antenna element that achieves high radiation efficiency under dual band [15]. In [5], a novel dual-band frequency reconfigurable MIMO patch-slot antenna based on a microstrip feedline is designed, which has a compact size and strong isolation. Inverted $\mathrm{F}$ structure is a good way to achieve dual-band MIMO antenna [16-18]. In [16], an inverted F-shaped radiator is used to realize dual-band MIMO antenna, which achieves better impedance matching by etching two U-shaped slits on a $50 \Omega$ feeder. The coplanar waveguide (CPW) feed structure is a single-plane structure 
that can achieve a wider bandwidth. At present, many CPW-fed dual-band MIMO antennas have been proposed, such as circularly polarized planar slot antenna [19] and dual-polarized loop-slot planar antenna [20].

In this paper, a CPW-fed dual-band MIMO antenna suitable for WLAN applications is presented. The presented antenna consists of two trapezoidal radiating elements, two rectangular slits, an L-shaped slit, and a defected ground plane. The rectangular slits and L-shaped slit are used to obtain good impedance matching in the lower and higher frequency bands, respectively. Parametric study has been carried out to further investigate the mechanism of the presented antenna.

\section{Antenna Geometry and Design}

The geometry of the proposed CPW-fed dual-band MIMO antenna is shown in Figure 1. The antenna is fabricated on a FR4 substrate with relative permittivity $\varepsilon_{r}$ of 4.4 , loss tangent $\delta$ of 0.02 , and thickness of $1.59 \mathrm{~mm}$. The radiating elements, the defected ground, and the isolation structure are all printed on one side of the substrate. The photograph of the manufactured antenna is shown in Figure 2.

The two identical antenna elements are perpendicular to each other. The antenna elements are fed by coplanar waveguides. The width of the CPW signal line is $3 \mathrm{~mm}$. The radiating element is composed of a trapezoidal patch with two rectangular slits, an L-shaped slit, and a semicircular slit. The L-shaped slit and rectangular slits can realize impedance matching at the lower and higher frequency bands, respectively. The length of the ground plane is $L_{1}$, and a rectangular stub with a length of $W_{8}$ and a width of $L_{5}$ is introduced at the middle of the ground plane to improve the isolation between two radiating elements.

To investigate the influence of the critical parameters on the frequency bands of the proposed antenna, the parametric study is carried out by changing the values of antenna dimensions. The current distribution of the presented antenna in different frequency bands is shown in Figure 3. Most of the surface currents are concentrated on the L-shaped slit and vertical rectangular slit at $2.45 \mathrm{GHz}$. At $5.5 \mathrm{GHz}$, the currents mainly concentrate along two rectangular slits. Therefore, we can adjust the dimension of the rectangular slit and the L-shaped slit to optimize the key performance of the antenna. Figure 4 illustrates the reflection coefficients of the presented antenna with different values of $W_{6}$ and $W_{14}$, respectively. In Figure 4(a), it can be observed that the value of $W_{6}$ mainly affects the lower frequency band. Figure 4 (b) shows the effect of different $W_{14}$ values on the higher frequencies. The optimum values of $W_{6}$ and $W_{14}$ are $2.1 \mathrm{~mm}$ and $7.2 \mathrm{~mm}$, respectively.

The strong isolation between the two antenna elements is mainly achieved by introducing rectangular stub and defected ground structure. The isolation performance of the MIMO antenna with and without rectangular stub is shown in Figure 5. It can be seen that the isolation is enhanced obviously with rectangle stub at the operating band. The final dimensions of the proposed antenna are listed in Table 1.

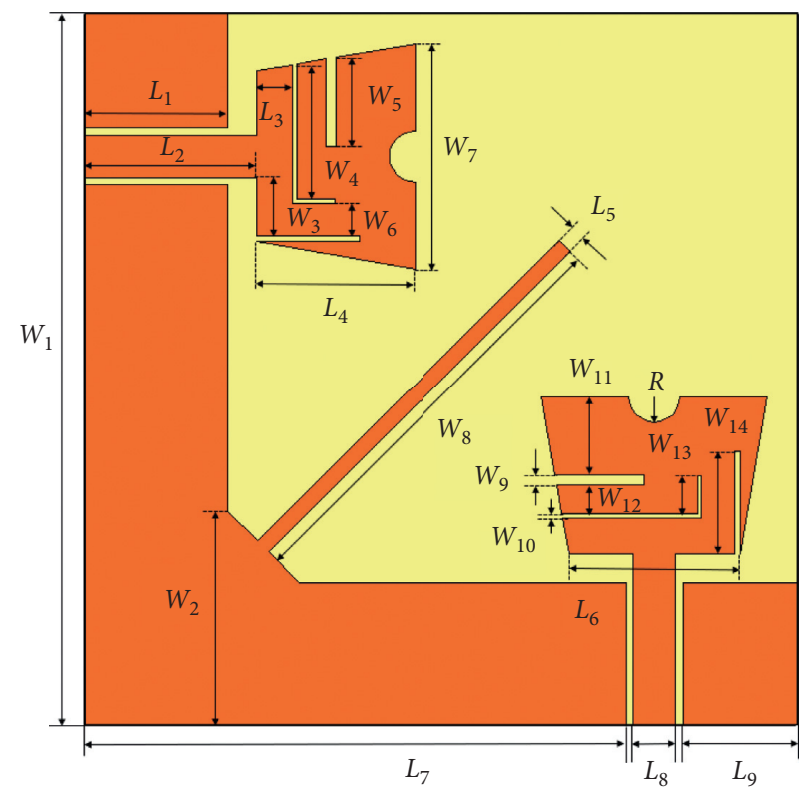

FIGURE 1: Geometry of the proposed antenna.

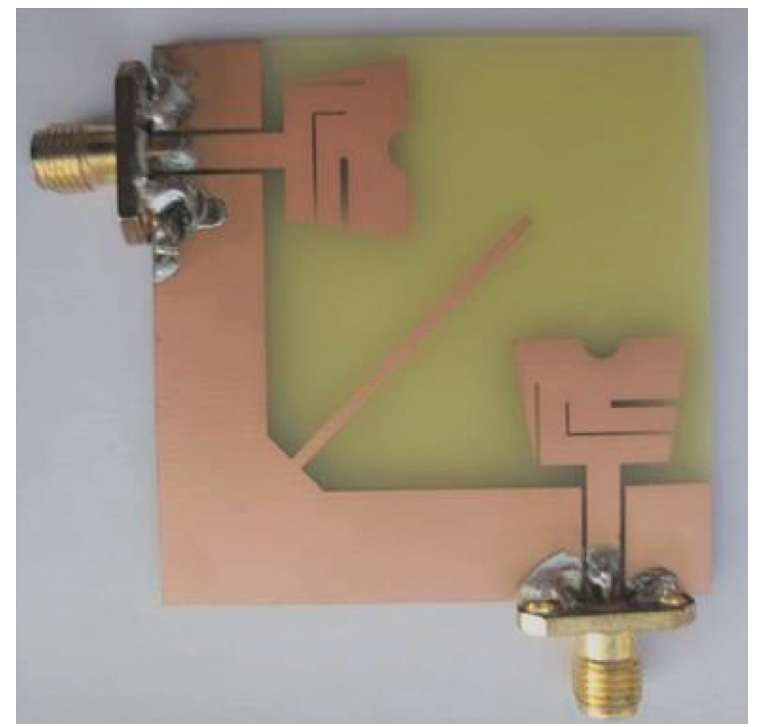

FIgURe 2: Photograph of the manufactured antenna.

\section{Results and Discussion}

Figure 6 shows the simulated and measured S-parameter. There is a little difference between the measurement results and the simulation results, which may be caused by measurement errors. From the measurement results, we can see that the bandwidth with reflection coefficient $S_{11}$ less than $-10 \mathrm{~dB}$ is $900 \mathrm{MHz} \quad(2.25-3.15 \mathrm{GHz})$ and $1060 \mathrm{MHz}$ $(4.89-5.95 \mathrm{GHz})$. The realized two frequency bands can cover $802.11 \mathrm{a} / \mathrm{b} / \mathrm{g}$ (WLAN, $2.4-2.4835 \mathrm{GHz}, 5.15-5.875 \mathrm{GHz}$ ) frequency bands. The measured mutual coupling $S_{21}$ between the two antenna elements is less than $-15 \mathrm{~dB}$ in the desired frequency bands $(2.4-2.4835 \mathrm{GHz}, 5.15-5.875 \mathrm{GHz})$. The designed antenna shows good isolation performance in the desired frequency band. 

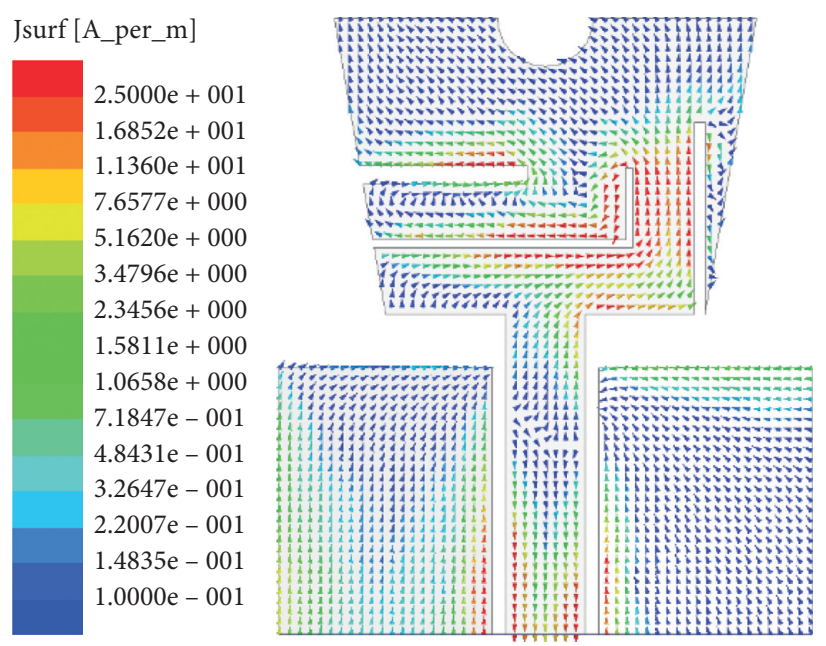

(a)

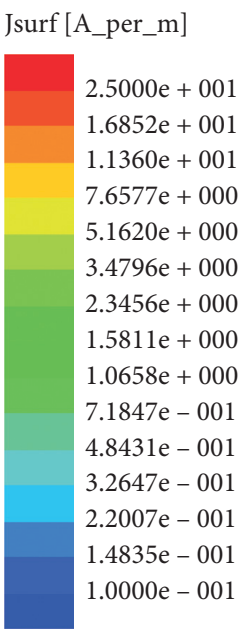

FIGURE 3: Surface current distributions at (a) $2.45 \mathrm{GHz}$ and (b) $5.5 \mathrm{GHz}$.

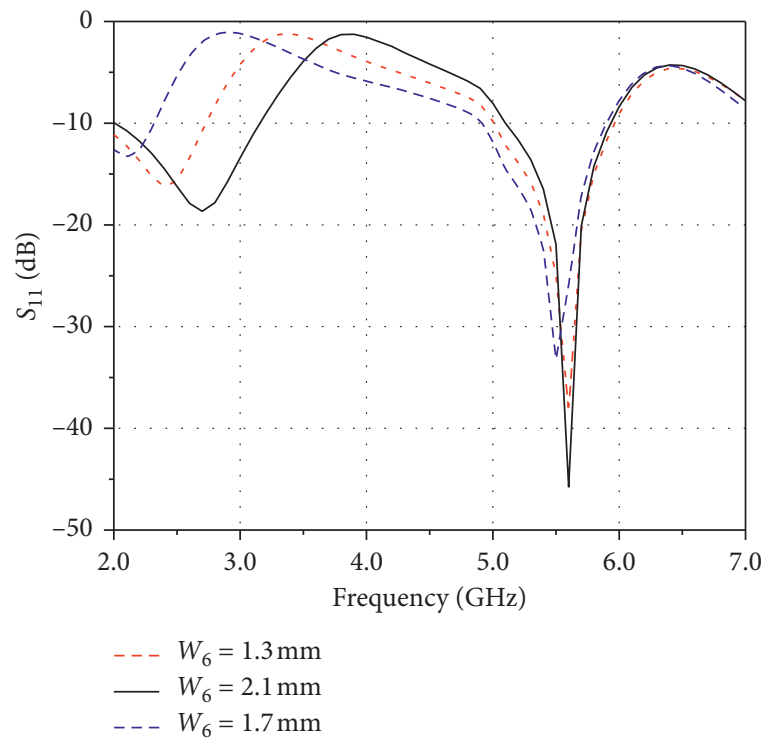

(a)

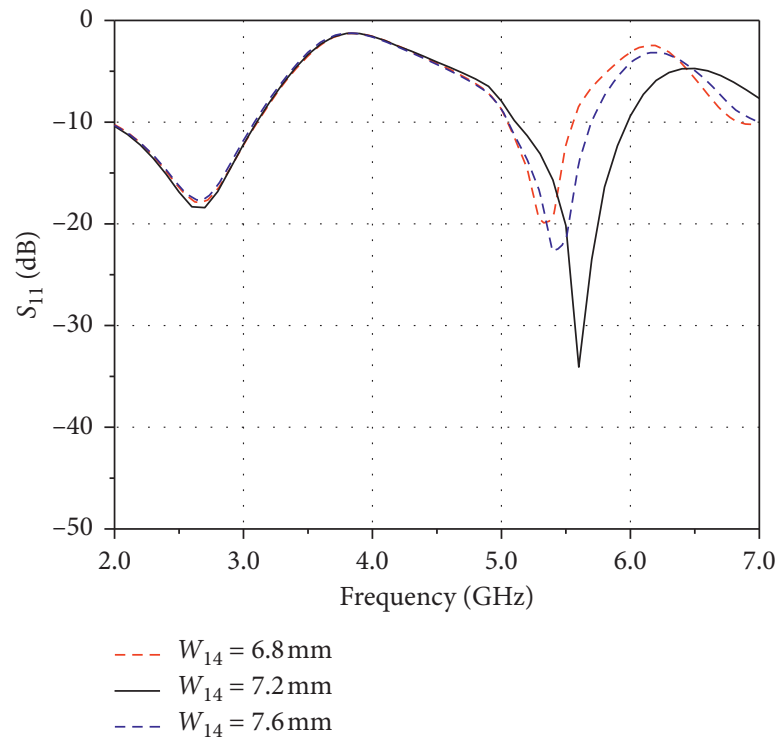

(b)

FIgURE 4: Simulated reflection coefficients for different values of (a) $W_{6}$ and (b) $W_{14}$.

Figure 7 shows the simulated and measured normalized $E$-plane and $H$-plane radiation patterns at $2.45 \mathrm{GHz}$ and $5.5 \mathrm{GHz}$. Since the proposed antenna structure is symmetrical, one port is fixed and the other port is connected to a $50 \Omega$ load during measurement.

The measured peak gain and total efficiency are shown in Figure 8. The measured gain is $5.59 \mathrm{dBi}$ at $2.45 \mathrm{GHz}$ and $5.63 \mathrm{dBi}$ at $5.5 \mathrm{GHz}$. The measured antenna efficiency is $77.8 \%$ and $80.4 \%$ in the lower and higher frequency bands, respectively.

\section{MIMO Antenna Diversity Performance}

Diversity performance of the designed MIMO antenna is mainly judged in terms of envelope correlation coefficient
(ECC), diversity gain (DG), total active reflection coefficient (TARC), and channel capacity loss (CCL).

For MIMO antenna, the envelope correlation coefficient (ECC) can be used for diversity performance evaluation. ECC $\left(\rho_{e}\right)$ can be calculated using radiation patterns of two antennas as follows [5]:

$$
\rho_{e}=\frac{\left|\iint_{4 \pi}\left[\overrightarrow{F_{1}}(\theta, \phi) \cdot \overrightarrow{F_{2}}(\theta, \phi)\right] \mathrm{d} \Omega\right|^{2}}{\iint_{4 \pi}\left|\overrightarrow{F_{1}}(\theta, \phi)\right|^{2} \mathrm{~d} \Omega \iint_{4 \pi}\left|\overrightarrow{F_{2}}(\theta, \phi)\right|^{2} \mathrm{~d} \Omega},
$$

where $\vec{F}_{i}(\theta, \phi)$ is the radiation patterns related to $i$ antenna element, and another antenna is terminated by a matched load. Since the lower envelope correlation leads to a larger channel capacity, the ECC value is required to be less than 


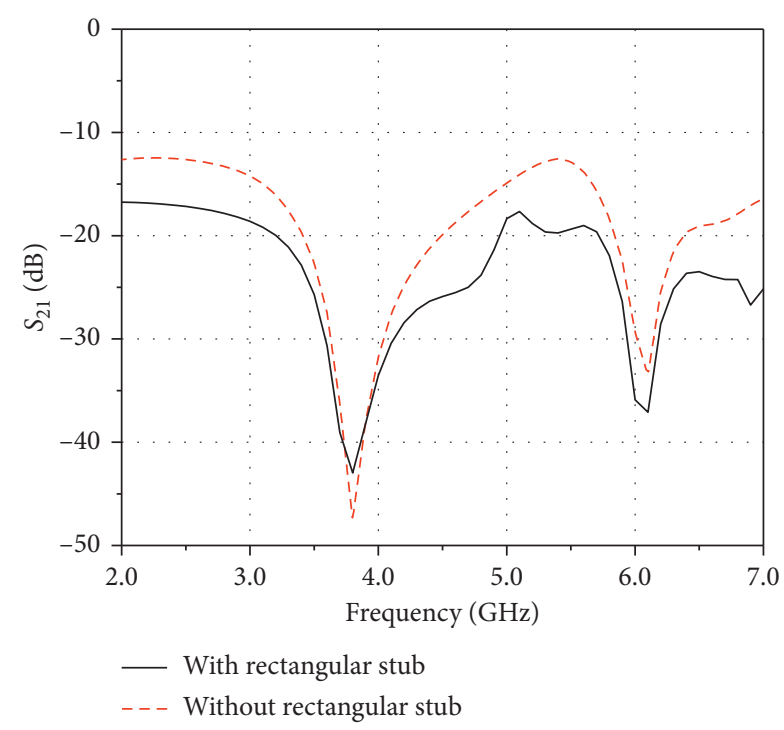

FIGURE 5: The isolation performance of the MIMO antenna with and without rectangular stub.

TABle 1: Dimensions of the proposed antenna (unit: $\mathrm{mm}$ ).

\begin{tabular}{lc}
\hline Parameters & Value \\
\hline$W_{1}$ & 50 \\
$W_{2}$ & 15 \\
$W_{3}$ & 4.1 \\
$W_{4}$ & 9.5 \\
$W_{5}$ & 6.3 \\
$W_{6}$ & 2.1 \\
$W_{7}$ & 16 \\
$W_{8}$ & 30 \\
$W_{9}$ & 0.7 \\
$W_{10}$ & 0.3 \\
$W_{11}$ & 5.4 \\
$W_{12}$ & 2.1 \\
$W_{13}$ & 3 \\
$W_{14}$ & 7.2 \\
$L_{1}$ & 10 \\
$L_{2}$ & 12 \\
$L_{3}$ & 2.5 \\
$L_{4}$ & 11.1 \\
$L_{5}$ & 1.1 \\
$L_{6}$ & 11.1 \\
$L_{7}$ & 1.1 \\
$L_{8}$ & 12 \\
$L_{9}$ & 8 \\
$R$ &
\end{tabular}

0.5. As we can observe from Figure 9, the ECC values at the lower and higher frequencies are lower than 0.003 and 0.01 , respectively.

The diversity gain of the two-element MIMO antenna can be calculated as

$$
\mathrm{DG}=10 \times \sqrt{1-\left|\rho_{e}\right|} .
$$

Generally, the acceptable DG value should be close to $10 \mathrm{~dB}$. As shown in Figure 9, the diversity gain of the

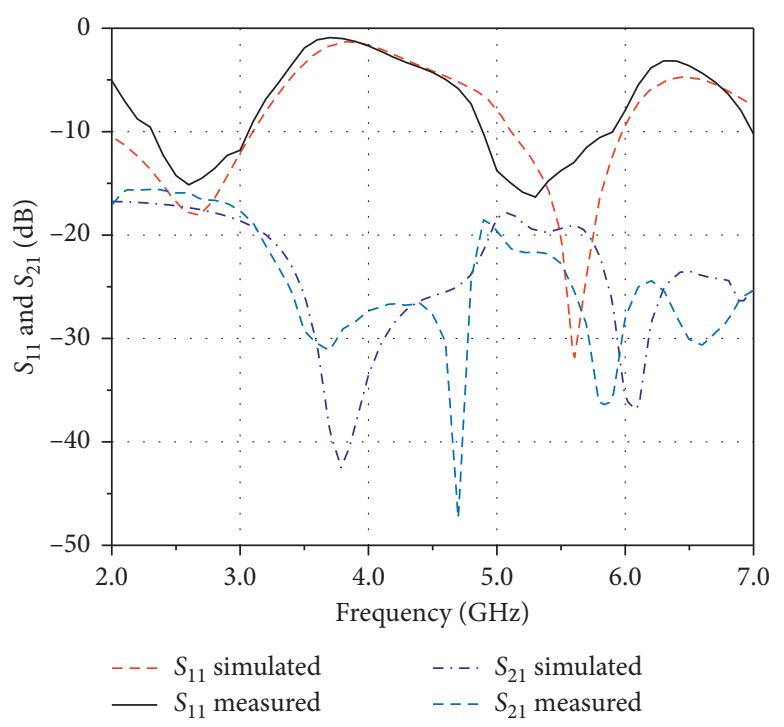

Figure 6: Simulated and measured S-parameter of the proposed antenna.

proposed MIMO antenna in the desired frequency band is 9.99 and 9.95 , respectively.

In a 2-port antenna system, adjacent antenna elements will interfere with each other when they work at the same time. The performance of the actual MIMO antenna system will not be predicted only by $S$ parameters, so another important parameter, TARC $\left(\Gamma_{a}^{t}\right)$, is explored to verify the diversity performance of the MIMO antenna system. TARC provides information about the return loss of a MIMO antenna system, which can be calculated as

$$
\Gamma_{a}^{t}=\sqrt{\frac{\left|S_{11}+S_{12} e^{j \theta}\right|^{2}+\left|S_{21}+S_{22} e^{j \theta}\right|^{2}}{2}}
$$

where $\theta$ represents the phase difference between the excitation signals. For MIMO wireless communication system, the TARC should be less than $0 \mathrm{~dB}$. As shown in Figure 10, the TARC value of the designed MIMO antenna is less than $-20 \mathrm{~dB}$ in the desired frequency band. Therefore, the designed antenna has good diversity performance.

For MIMO antenna systems, the upper limit of the information transmission rate in the wireless communication channel can be judged by the channel capacity loss (CCL), and usually the CCL should be less than $0.5 \mathrm{bits} / \mathrm{sec} /$ Hz. CCL can be expressed as

$$
\operatorname{CCL}(\text { loss })=-\log _{2} \operatorname{det}\left(\psi^{R}\right),
$$

where $\psi^{P}$ is the element matrix, which provides the performance of the MIMO system. For a two-port antenna, $\psi^{P}$ can be expressed as

$$
\left(\psi^{R}\right)=\left[\begin{array}{ll}
\rho_{11} & \rho_{12} \\
\rho_{21} & \rho_{22}
\end{array}\right] .
$$

Matrix elements can be obtained through $S$ parameters: 


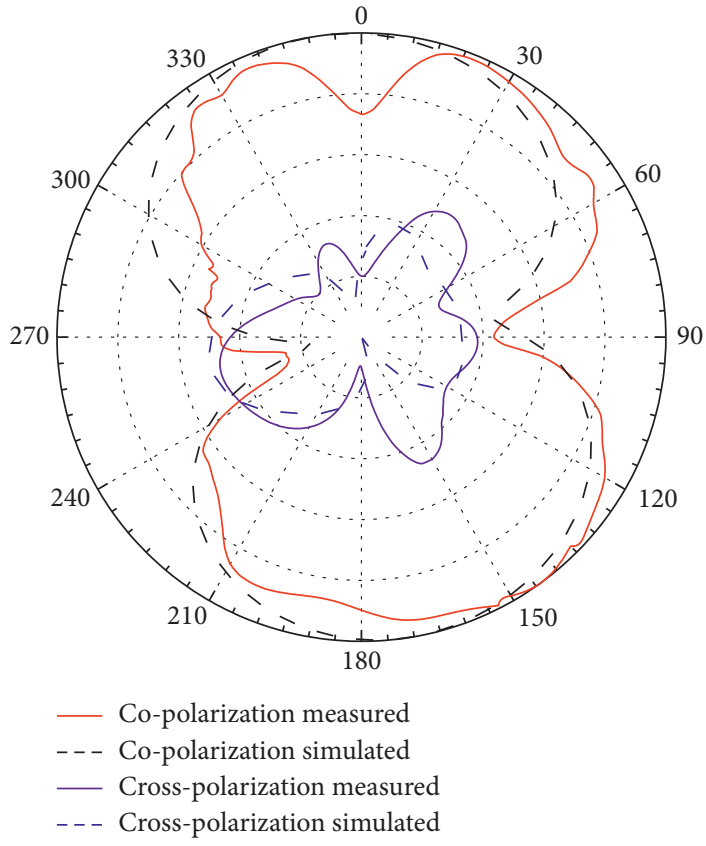

(a)

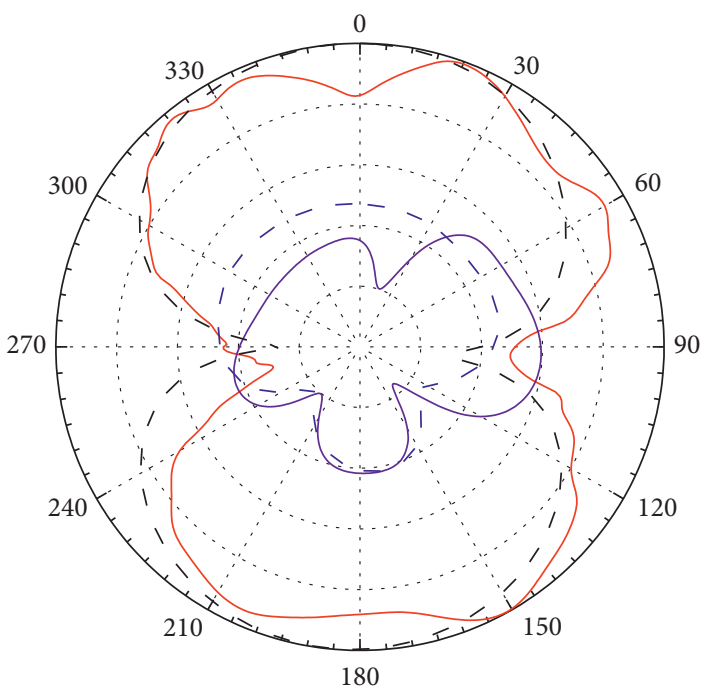

- Co-polarization measured

- - - Co-polarization simulated

- Cross-polarization measured

- - Cross-polarization simulated

(c)

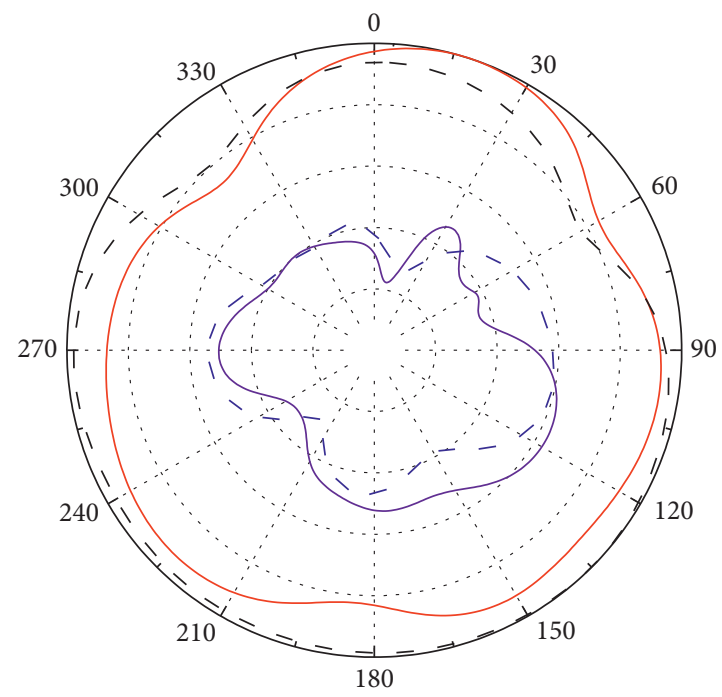

- Co-polarization measured
- - Co-polarization simulated
— Cross-polarization measured
- - Cross-polarization simulated

(b)

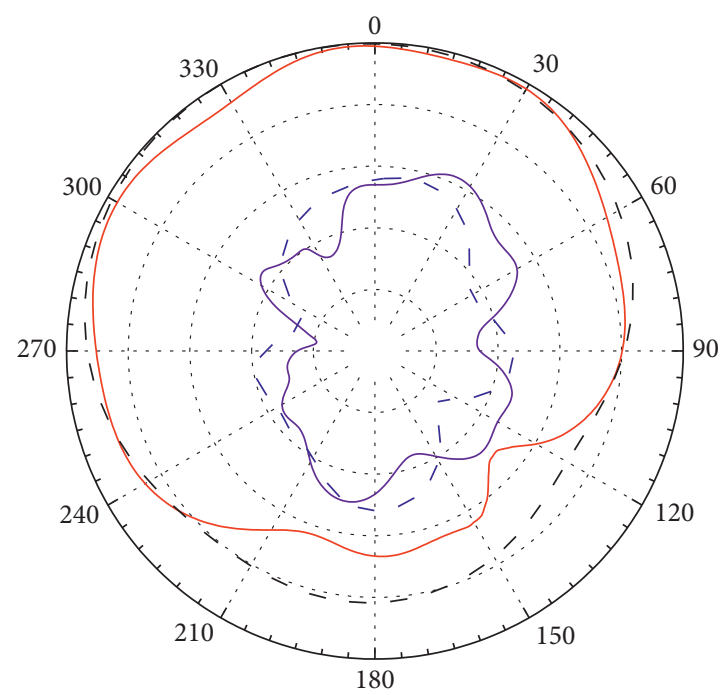

_ Co-polarization measured

- - - Co-polarization simulated

— Cross-polarization measured

- - - Cross-polarization simulated

(d)

Figure 7: Measured and simulated radiation patterns of the proposed antenna: (a) $2.45 \mathrm{GHz} E$-plane, (b) $2.45 \mathrm{GHz} H$-plane, (c) $5.5 \mathrm{GHz}$ E-plane, and (d) $5.5 \mathrm{GHz} H$-plane.

$$
\begin{aligned}
& \rho_{i i}=1-\left(\sum_{n=1}^{N}\left|S_{i n}^{*} S_{n i}\right|\right)=1-\left(\left|S_{11}\right|^{2}+\left|S_{12}\right|^{2}\right), \\
& \rho_{i j}=-\left[\sum_{n=1}^{N}\left|S_{i n}^{*} S_{n j}\right|\right]=-\left(S_{11}^{*} S_{12}+S_{12}^{*} S_{22}\right),
\end{aligned}
$$

where $i=1, j=2$, and $n=1,2$. The measured result of CCL is depicted in Figure 10. It can be seen that CCL has lower values of 0.2 and 0.1 at $2.45 \mathrm{GHz}$ and $5.5 \mathrm{GHz}$.

Finally, Table 2 summarizes the performance comparison between the proposed MIMO antenna and the other reported antennas. From the comprehensive comparison, it 


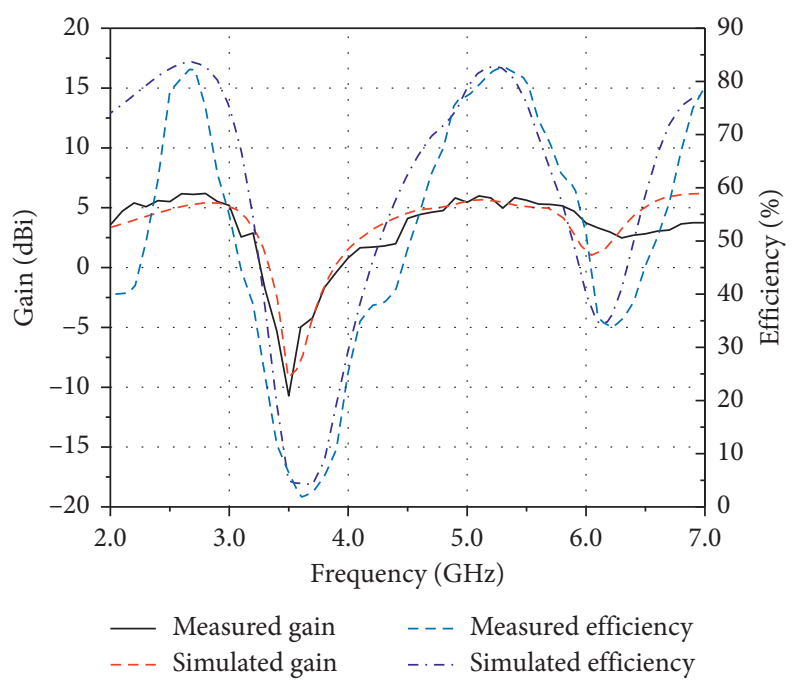

Figure 8: Simulated and measured gain and efficiency.

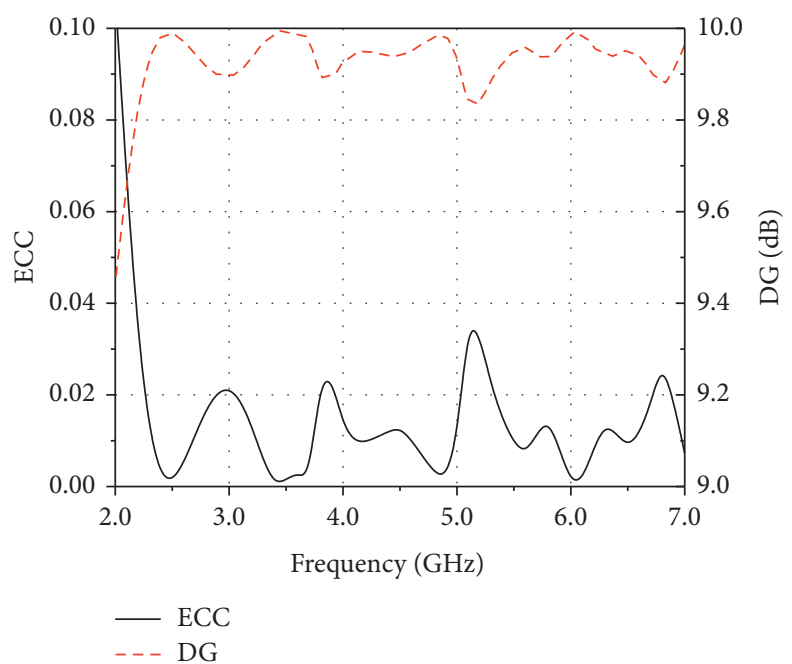

FIgURE 9: Measured ECC and DG results of the proposed MIMO antenna.

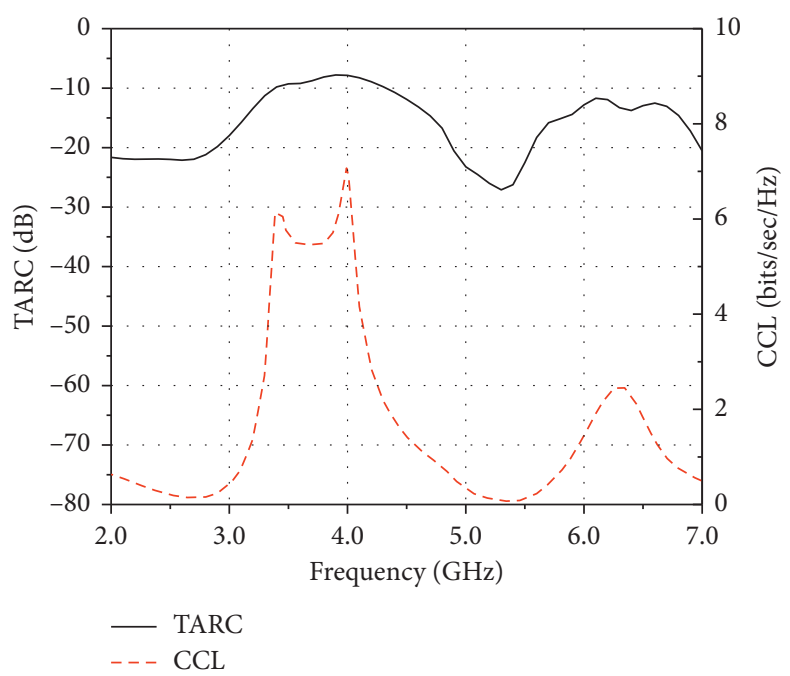

FIgURE 10: TARC and CCL of the proposed MIMO antenna. 
TABLE 2: Comparison between the proposed MIMO antenna and other reported antennas.

\begin{tabular}{|c|c|c|c|c|c|}
\hline Reference & Size $\left(\mathrm{mm}^{3}\right)$ & Matching bands $(\mathrm{GHz})$ & Gain $(\mathrm{dBi})$ & Efficiency (\%) & ECC \\
\hline \multirow{2}{*}{ [12] } & \multirow{2}{*}{$50 \times 50 \times 1.59$} & $2.09-2.86$ & 1.74 & 44.5 & \multirow[t]{2}{*}{0.03} \\
\hline & & $5.05-5.94$ & 4.5 & 65.9 & \\
\hline \multirow{3}{*}{ [21] } & \multirow{3}{*}{$54 \times 22 \times 1.6$} & $2.44-2.47$ & 5.49 & \multirow{3}{*}{-} & $<0.03$ \\
\hline & & $3.44-3.50$ & 4.57 & & $<0.035$ \\
\hline & & $5.15-5.48$ & 0.80 & & $<0.005$ \\
\hline$[22]$ & $83.8 \times 83.8 \times 15$ & $2.23-2.91$ & 7.02 & 82.1 & - \\
\hline \multirow{2}{*}{ [23] } & \multirow{2}{*}{$21 \times 46 \times 1.6$} & $3.4-3.6$ & 3.25 & $>75.1$ & \multirow{2}{*}{$<0.003$} \\
\hline & & 4-8 & 3.40 & $>74.2$ & \\
\hline \multirow{2}{*}{ Proposed } & \multirow{2}{*}{$50 \times 50 \times 1.59$} & $2.25-3.15$ & 5.59 & 77.8 & $<0.003$ \\
\hline & & $4.89-5.95$ & 5.63 & 80.4 & $<0.01$ \\
\hline
\end{tabular}

is observed that the proposed antenna has shown higher gain and efficiency. The proposed MIMO antenna supports dualfrequency operation and has low ECC, which can guarantee good MIMO performance.

\section{Conclusions}

A novel coplanar waveguide- (CPW-) fed dual-band antenna is proposed. By embedding rectangular slits and L-shaped slit in two identical trapezoidal patch elements, the dual-frequency operation of the designed antenna can be realized. The proposed antenna is manufactured on a FR4 substrate with the size of $50 \times 50 \times 1.59 \mathrm{~mm}^{3}$. Moreover, the proposed antenna exhibits good isolation performance and stable radiation patterns in the desired frequency bands. The proposed antenna is a suitable candidate for IEEE 802.11 $\mathrm{a} / \mathrm{b} / \mathrm{g}$ applications.

\section{Data Availability}

The data used to support the findings of this study are available from the corresponding author upon request.

\section{Conflicts of Interest}

The authors declare that there are no conflicts of interest regarding the publication of this paper.

\section{Acknowledgments}

This study was supported in part by the National Natural Science Foundation of China under grant no. 61671330, the Science and Technology Department of Zhejiang Province under grant no. LGG19F010009, and the Wenzhou Municipal Science and Technology Program under grant nos. C20170005 and 2018ZG019.

\section{References}

[1] C.-Y.-D. Sim, C.-C. Chen, X. Y. Zhang, Y.-L. Lee, and C.-Y. Chiang, "Very small-size uniplanar printed monopole antenna for dual-band WLAN laptop computer applications," IEEE Transactions on Antennas and Propagation, vol. 65, no. 6, pp. 2916-2922, 2017.

[2] J. Huang, G. Dong, Q. Cai, Z. Chen, L. Li, and G. Liu, "Dualband MIMO antenna for 5G/WLAN mobile terminals," Micromachines, vol. 12, no. 5, pp. 489-501, 2021.
[3] Y. He, K. Ma, N. Yan, and H. Zhang, "Dual-band monopole antenna using substrate-integrated suspended line technology for WLAN application," IEEE Antennas and Wireless Propagation Letters, vol. 16, pp. 2776-2779, 2017.

[4] Z. Niu, H. Zhang, Q. Chen, and T. Zhong, "Isolation enhancement in closely coupled dual-band MIMO patch antennas," IEEE Antennas and Wireless Propagation Letters, vol. 18, no. 8, pp. 1686-1690, 2019.

[5] X. Zhao and S. Riaz, "A dual-band frequency reconfigurable MIMO patch-slot antenna based on reconfigurable microstrip feedline," IEEE Access, vol. 6, pp. 41450-41457, 2018.

[6] X. Tan, W. Wang, Y. Wu, Y. Liu, and A. A. Kishk, "Enhancing isolation in dual-band meander-line multiple antenna by employing split EBG structure," IEEE Transactions on Antennas and Propagation, vol. 67, no. 4, pp. 2769-2774, 2019.

[7] B. L. Dhevi, K. S. Vishvaksenan, and K. Rajakani, "Isolation enhancement in dual-band microstrip antenna array using asymmetric loop resonator," IEEE Antennas and Wireless Propagation Letters, vol. 17, no. 2, pp. 238-241, 2018.

[8] Y. Li, C.-Y.-D. Sim, Y. Luo, and G. Yang, "High-isolation 3.5 $\mathrm{GHz}$ eight-antenna MIMO array using balanced open-slot antenna element for 5G smartphones," IEEE Transactions on Antennas and Propagation, vol. 67, no. 6, pp. 3820-3830, 2019.

[9] S.-W. Su, C.-T. Lee, and Y.-W. Hsiao, "Compact twoinverted-F-antenna system with highly integrated $\$ \backslash$ pi $\$$ shaped decoupling structure," IEEE Transactions on Antennas and Propagation, vol. 67, no. 9, pp. 6182-6186, 2019.

[10] R. Yang, S. Xi, Q. Cai, Z. Chen, X. Wang, and G. Liu, “A compact planar dual-band multiple-input and multiple-output antenna with high isolation for 5G and 4G applications," Micromachines, vol. 12, no. 5, pp. 544-551, 2021.

[11] Z. Ren, A. Zhao, and S. Wu, "MIMO antenna with compact decoupled antenna pairs for $5 \mathrm{G}$ mobile terminals," IEEE Antennas and Wireless Propagation Letters, vol. 18, no. 7, pp. 1367-1371, 2019.

[12] J. Bai, R. Zhi, W. Wu, M. Shangguan, B. Wei, and G. Liu, “A novel multiband MIMO antenna for TD-LTE and WLAN applications," Progress in Electromagnetics Research Letters, vol. 74, pp. 131-136, 2018.

[13] W. Y. Wu, R. X. Zhi, Y. Chen, H. Li, and G. Liu, "A compact multiband MIMO antenna for IEEE $802.11 \mathrm{a} / \mathrm{b} / \mathrm{g} / \mathrm{n}$ applications," Progress in Electromagnetics Research Letters, vol. 84, pp. 59-65, 2019.

[14] J. L. Huang, G. T. Dong, J. Cai, H. Li, and G. Liu, “A quad-port dual-band MIMO antenna array for 5G smartphone applications," Electronics, vol. 10, no. 5, pp. 1-9, 2021.

[15] S. Nandi and A. Mohan, "A compact dual-band MIMO slot antenna for WLAN applications," IEEE Antennas and Wireless Propagation Letters, vol. 16, pp. 2457-2460, 2017. 
[16] J. Deng, J. Li, L. Zhao, and L. Guo, "A dual-band inverted-F MIMO antenna with enhanced isolation for WLAN applications," IEEE Antennas and Wireless Propagation Letters, vol. 16, pp. 2270-2273, 2017.

[17] D. Q. Liu, M. Zhang, H. J. Luo, H. L. Wen, and J. Wang, "Dual-band platform-free PIFA for 5G MIMO application of mobile devices," IEEE Transactions on Antennas and Propagation, vol. 66, no. 11, pp. 6328-6333, 2018.

[18] W. Hu, X. Liu, S. Gao et al., "Dual-band ten-element MIMO array based on dual-mode IFAs for 5G terminal applications," IEEE Access, vol. 7, pp. 178476-178485, 2019.

[19] H.-G. Xue, X.-X. Yang, and Z. Ma, "A novel microstrip-CPW fed planar slot antenna with broadband and circular polarization," IEEE Antennas and Wireless Propagation Letters, vol. 14, pp. 1392-1395, 2015.

[20] M.-T. Tan and B.-Z. Wang, "A compact dual-band dualpolarized loop-slot planar antenna," IEEE Antennas and Wireless Propagation Letters, vol. 14, pp. 1742-1745, 2015.

[21] M. Ameen, O. Ahmad, and R. K. Chaudhary, "Bandwidth and gain enhancement of triple-band MIMO antenna incorporating metasurface-based reflector for WLAN/WiMAX applications," IET Microwaves, Antennas \& Propagation, vol. 14, no. 13, pp. 1493-1503, 2020.

[22] M. Ameen, O. Ahmad, and R. K. Chaudhary, "Wideband circularly-polarised high-gain diversity antenna loaded with metasurface reflector for small satellite applications," Electronics Letters, vol. 55, no. 15, pp. 829-831, 2019.

[23] M. Ameen, O. Ahmad, and R. K. Chaudhary, "Single split-ring resonator loaded self-decoupled dual-polarized MIMO antenna for mid-band 5G and C-band applications," AEU-International Journal of Electronics and Communications, vol. 124, Article ID 153336, 2020. 